\title{
Complete genome of Pieris rapae, a resilient alien, a cabbage pest, and a source of anti-cancer proteins [version 1; peer
}

\section{review: 2 approved]}

\author{
Jinhui Shen ${ }^{1 *}$, Qian Cong ${ }^{1 *}$, Lisa N. Kinch², Dominika Borek1, \\ Zbyszek Otwinowski1 ${ }^{1}$ Nick V. Grishin (D)1,2
}

\footnotetext{
${ }^{1}$ Departments of Biophysics and Biochemistry, University of Texas Southwestern Medical Center, Dallas, USA

${ }^{2}$ Howard Hughes Medical Institute, University of Texas Southwestern Medical Center, Dallas, USA

* Equal contributors
}

\begin{tabular}{l} 
V1 First published: 03 Nov 2016, 5:2631 \\
https://doi.org/10.12688/f1000research.9765.1 \\
Latest published: 03 Nov 2016, 5:2631 \\
https://doi.org/10.12688/f1000research.9765.1 \\
\hline
\end{tabular}

\section{Abstract}

The Small Cabbage White (Pieris rapae) is originally a Eurasian butterfly. Being accidentally introduced into North America, Australia, and New Zealand a century or more ago, it spread throughout the continents and rapidly established as one of the most abundant butterfly species. Although it is a serious pest of cabbage and other mustard family plants with its caterpillars reducing crops to stems, it is also a source of pierisin, a protein unique to the Whites that shows cytotoxicity to cancer cells. To better understand the unusual biology of this omnipresent agriculturally and medically important butterfly, we sequenced and annotated the complete genome from USA specimens. At $246 \mathrm{Mbp}$, it is among the smallest Lepidoptera genomes reported to date. While $1.5 \%$ positions in the genome are heterozygous, they are distributed highly non-randomly along the scaffolds, and nearly $20 \%$ of longer than 1000 base-pair segments are SNP-free (median length: 38000 bp). Computational simulations of population evolutionary history suggest that American populations started from a very small number of introduced individuals, possibly a single fertilized female, which is in agreement with historical literature. Comparison to other Lepidoptera genomes reveals several unique families of proteins that may contribute to the unusual resilience of Pieris. The nitrile-specifier proteins divert the plant defense chemicals to non-toxic products. The apoptosis-inducing pierisins could offer a defense mechanism against parasitic wasps. While only two pierisins from Pieris rapae were characterized before, the genome sequence revealed eight, offering additional candidates as anti-cancer drugs. The reference genome we obtained lays the foundation for future studies of the Cabbage White and other Pieridae species.

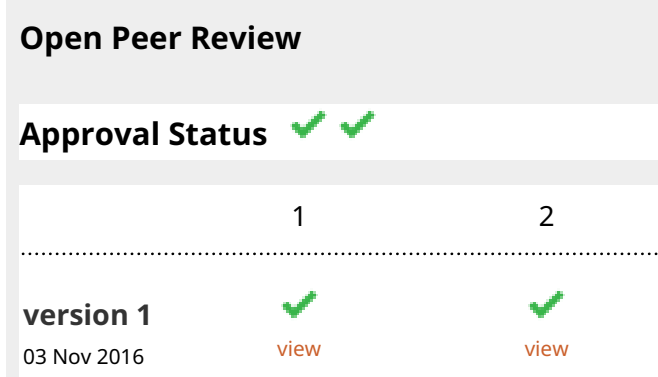

1. James Mallet, Harvard University, Cambridge, USA

2. Andrei Sourakov (D), University of Florida, Gainesville, USA

Any reports and responses or comments on the article can be found at the end of the article. 
Keywords

Butterfly genomics, Invasive species, Crop pest, Pieridae, Population

history

Corresponding author: Nick V. Grishin (grishin@chop.swmed.edu)

Competing interests: The authors declare that they have no competing interests

Grant information: This work was supported in part by the National Institutes of Health (GM094575 to N.V.G) and the Welch Foundation (I-1505 to N.V.G).

The funders had no role in study design, data collection and analysis, decision to publish, or preparation of the manuscript.

Copyright: @ 2016 Shen J et al. This is an open access article distributed under the terms of the Creative Commons Attribution License, which permits unrestricted use, distribution, and reproduction in any medium, provided the original work is properly cited. Data associated with the article are available under the terms of the Creative Commons Zero "No rights reserved" data waiver (CCO 1.0 Public domain dedication).

How to cite this article: Shen J, Cong Q, Kinch LN et al. Complete genome of Pieris rapae, a resilient alien, a cabbage pest, and a source of anti-cancer proteins [version 1; peer review: 2 approved] F1000Research 2016, 5:2631

https://doi.org/10.12688/f1000research.9765.1

First published: 03 Nov 2016, 5:2631 https://doi.org/10.12688/f1000research.9765.1 


\section{Introduction}

The Small Cabbage White (Pieris rapae, Figure 1), also known as European Cabbage Butterfly, or Imported Cabbageworm, is one of the most common and widely spread butterflies in North America, ranging from Southern Canada to Mexico ${ }^{1}$. While mostly present in disturbed open habitats, it also invades valley bottoms, mountain tops, and forested areas ${ }^{2}$. In many northeastern USA states, it frequently outnumbers all other butterflies combined ${ }^{3}$. North American populations of the Cabbage Whites, currently numbering in billions, are likely a progeny of a single female accidentally introduced to Quebec, Canada during the second half of the $19^{\text {th }}$ century ${ }^{4,5}$. By the beginning of the $20^{\text {th }}$ century it had reached California Coast ${ }^{6}$. Around the same time, it was introduced into Hawaii, New Zealand and Australia ${ }^{6,7}$. Originally from Eurasia and Northern Africa ${ }^{1}$, Cabbage White has become one of the most ubiquitous butterfly species. The reasons for its population expansion across variable habitats as well as the population history of American invasion are poorly understood.

While only very few butterflies are agricultural pests, the Small White is notorious for reducing cabbage plants to stems. Going through its life-cycle quickly and having up to 6 generations per year ${ }^{8}$, it is a serious pest of the mustard family crops ${ }^{5,9}$. In addition to damaging plants, caterpillars contaminate and stain produce with feces.

These butterflies are also a source of a protein with anti-cancer properties ${ }^{10}$. Aptly termed pierisin, this enzyme of a probable bacterial origin is unique to Pieris and its close relatives among Lepidoptera species ${ }^{10,11}$. Pierisin contains an $\mathrm{N}$-terminal ADP-ribosylation catalytic domain followed by four ricin domains, and it can induce apoptosis and thus contribute to metamorphosis and resistance to parasitoids ${ }^{11,12}$. Due to its cytotoxic effects on many cancer cell lines, pierisin is an unexpected protein of medical importance ${ }^{10}$. Agricultural and medical significance of the Cabbage White has attracted broad attention from researchers and the general public. However, the lack of complete genome sequence hinders these studies.

To aid genetics, evolutionary, and biochemical studies of the Cabbage White, we sequenced and annotated its complete genome from North American specimens. At $246 \mathrm{Mbp}$, it is one of the smallest genomes among Lepidoptera genomes assembled to this day, and the first representative from the Pierinae subfamily. Overall, this diploid genome contains $1.5 \%$ heterozygous positions that is consistent with the expected high level of butterfly's heterozygosity. However, the Pieris genome contains a large number of SNP-free segments that are at least $1000 \mathrm{bp}$ long (with the median length equal to $38000 \mathrm{bp}$ ), which together constitute $18.3 \%$ of the assembled genome. This number is below $4 \%$ in other species. The high fraction of homozygous segments indicates low genetic diversity of the population, which supports the hypothesis that Cabbage White expansion in America started from a very small number of individuals, which could be as low as 1 or 2 fertilized females.

Comparison to other Lepidoptera genomes reveals several unique families of proteins that may contribute to the unusual resilience and adaptability of Pieris. For instance, the nitrile-specifier proteins, which converts plant defense chemicals to non-toxic molecules ${ }^{13}$ are unique to these species. The apoptosis-inducing pierisins could offer a defense mechanism against parasitic wasps. While only two pierisins from Pieris rapae were characterized before ${ }^{14,15}$, the genome sequencing revealed eight genes coding for pierisins, offering additional candidates for anti-cancer drugs development. The reference genome we obtained lays the foundation for future studies of the Cabbage White and other species of Pieridae.

\section{Results and discussion}

Genome assembly, annotation, and comparison to other Lepidoptera genomes

We assembled a $246 \mathrm{Mb}$ reference genome of Pieris rapae (Pra), which is one of the smallest among currently sequenced Lepidoptera genomes (Supplementary Table S1A) ${ }^{16-26}$. The scaffold N50 of Pra genome assembly is $617 \mathrm{~kb}$, better than many other published Lepidoptera genomes (Table 1). The genome assembly is also better than many other Lepidoptera genomes in terms of completeness measured by the presence of Core Eukaryotic Genes Mapping Approach (CEGMA) genes (Supplementary Table S1B) ${ }^{27}$, cytoplasmic ribosomal proteins and independently assembled transcripts (Table 1). The genome sequence has been deposited at DDBJ/EMBL/GenBank under the accession LWME00000000. The version described in this paper is version LWME01000000. In addition, the main results from genome assembly, annotation and analysis can be downloaded at http://prodata.swmed.edu/LepDB/.

We assembled the transcriptome of Pra using another specimen (NVG-3537) from the same locality. Based on the transcriptome,

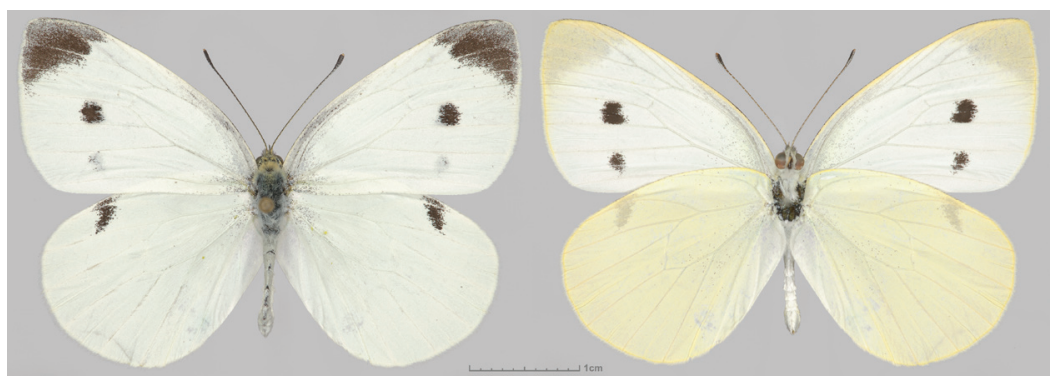

Figure 1. Pieris rapae specimen used for the paired-end genomic library constructions. Dorsal (left) and ventral (right) views are shown. Voucher NVG-4113, male, USA: Texas: Dallas Co., Dallas, GPS 32.90516, -96.81546, 17-Jul-2015. 
Table 1. Quality and composition of Lepidoptera genomes.

\begin{tabular}{|c|c|c|c|c|c|c|c|c|c|c|c|c|c|}
\hline Feature & Pra & Pse & $P g l$ & Ppo & $P x u$ & Dpl & Hme & Mci & Cce & Lac & Mse & Bmo & Pxy \\
\hline Genome size (Mb) & 246 & 406 & 375 & 227 & 244 & 249 & 274 & 390 & 729 & 298 & 419 & 481 & 394 \\
\hline Genome size without gap (Mb) & 243 & 347 & 361 & 218 & 238 & 242 & 270 & 361 & 689 & 290 & 400 & 432 & 387 \\
\hline Heterozygosity (\%) & 1.5 & 1.2 & 2.3 & n.a. & n.a. & 0.55 & n.a. & n.a. & 1.2 & 1.5 & n.a. & n.a. & $\sim 2$ \\
\hline Scaffold N50 (kb) & 617 & 257 & 231 & 3672 & 6199 & 716 & 194 & 119 & 233 & 525 & 664 & 3999 & 734 \\
\hline CEGMA (\%) & 99.6 & 99.3 & 99.6 & 99.3 & 99.6 & 99.6 & 98.2 & 98.9 & 100 & 99.3 & 99.8 & 99.6 & 98.7 \\
\hline CEGMA coverage by single scaffold (\%) & 88.7 & 87.4 & 86.9 & 85.8 & 88.8 & 87.4 & 86.5 & 79.2 & 85.3 & 86.8 & 86.4 & 86.8 & 84.1 \\
\hline Cytoplasmic Ribosomal Proteins (\%) & 98.9 & 98.9 & 98.9 & 98.9 & 97.8 & 98.9 & 94.6 & 94.6 & 98.9 & 98.9 & 98.9 & 98.9 & 93.5 \\
\hline De novo assembled transcripts (\%) & 99 & 97 & 98 & n.a. & n.a. & 96 & n.a. & 97 & 97 & 98 & n.a. & 98 & 83 \\
\hline GC content (\%) & 32.7 & 39.0 & 35.4 & 34.0 & 33.8 & 31.6 & 32.8 & 32.6 & 37.1 & 34.4 & 35.3 & 37.7 & 38.3 \\
\hline Repeat (\%) & 22.7 & 17.2 & 22.0 & n.a. & n.a. & 16.3 & 24.9 & 28.0 & 34.0 & 15.5 & 24.9 & 44.1 & 34.0 \\
\hline Exon $(\%)$ & 7.9 & 6.20 & 5.07 & 5.11 & 8.59 & 8.40 & 6.38 & 6.36 & 3.11 & 6.96 & 5.34 & 4.03 & 6.35 \\
\hline Intron (\%) & 33.3 & 25.5 & 25.6 & 24.8 & 45.5 & 28.1 & 25.4 & 30.7 & 24.0 & 31.6 & 38.3 & 15.9 & 30.7 \\
\hline Number of proteins (thousands) & 13.2 & 16.5 & 15.7 & 15.7 & 13.1 & 15.1 & 12.8 & 16.7 & 16.5 & 17.4 & 15.6 & 14.3 & 18.1 \\
\hline Number of universal ortholog lost & 48 & 35 & 33 & 235 & 71 & 18 & 225 & 356 & 35 & 82 & 120 & 236 & 808 \\
\hline Number of species specific genes & 27 & 101 & 32 & 9 & 240 & 69 & 52 & 59 & 101 & 87 & 165 & 98 & 399 \\
\hline
\end{tabular}

n.a. Data not available

Pra: Pieris rapae; Lac: Lerema accius; Cce: Calycopis cecrops; Pgl: Pterourus glaucus; Dpl: Danaus plexippus; Hme: Heliconius melpomene; Mci: Melitaea cinxia; Bmo: Bombyx mori; Pxy: Plutella xylostella; Mse: Manduca sexta; Ppo: Papilio polytes; Pse: Phoebis sennae; Pxu: Papilio xuthus.

Heterozygosity: Calculated as the percent of heterozygous positions detected by the Genome Analysis Toolkit (GATK) for Pgl, Lac, Cce, Pra and Pse; or taken from information in the literature for $D p^{R 0}$; or estimated based on the histogram of K-mer frequencies for $P x y^{18,41}$.

homologs from other Lepidoptera and Drosophila melanogaster, de novo gene predictions, and repeat identification (Supplementary Table S2B), we predicted 13,188 protein-coding genes in the Pra genome (Supplementary Table S2C). $74.4 \%$ of these genes are likely expressed in the adult, as they fully or partially overlap with the transcripts. We annotated the putative functions of the 10,747 protein-coding genes (Supplementary Table S2D). Comparison of the protein sets from Lepidoptera species revealed the presence of some proteins unique to the Cabbage White and not present in other species. Among these are pierisins and nitrile-specifier proteins that play important roles in resistance against parasites and toxins from plants and contribute to the successful spread of Pieris rapae across continents.

\section{Phylogeny of Lepidoptera}

We identified orthologous proteins encoded by 13 Lepidoptera genomes (Plutella xylostella, Bombyx mori, Manduca sexta, Lerema accius, Papilio glaucus, Papilio polytes, Papilio xuthus, Phoebis sennae, Melitaea cinxia, Heliconius melpomene, Danaus plexippus, Calycopis cecrops and Pieris rapae) and detected 4906 universal orthologous groups, from which 1845 groups consist of a single-copy gene in each of the species. A phylogenetic tree built from the concatenated alignment of the single-copy orthologs using RAxML places Pieris as the sister to Phoebis (Figure 2), the only other member of the Pieridae family with sequenced genome. Our analysis places Papilionidae as a sister to all other butterflies, including skippers (Hesperiidae). Such placement contradicts morphology-based phylogeny, but is reproduced in all maximumlikelihood and Bayesian trees published recently ${ }^{26,28}$.
All nodes received $100 \%$ bootstrap support when the alignment of all single-copy orthologs was used. However, since bootstrap only measures internal consistency of phylogenetic signal in the alignment, very large datasets will almost always result in $100 \%$ support, even if the tree is incorrect and biased by various factors such as nucleotide composition and long branch attraction. To find the weakest nodes, we reduced the amount of data by randomly splitting the concatenated alignment of all single-copy orthologs into 100 alignments (about 3088 positions in each alignment). The consensus tree based on these alignments revealed that the node referring to relative position of skippers and swallowtails shows the lowest support (68\%) compared to other nodes, and their evolutionary history remains to be further investigated when better taxon sampling by complete genomes is achieved.

\section{Anti-cancer protein pierisin}

We identified 8 copies of the pierisin gene (Supplementary Table S3A), while only 2 copies were previously reported from Pieris rapae (GenBank) ${ }^{14,15}$. At least 7 pierisin copies are likely expressed, as their partial sequences are present in the RNA-seq data from adult. The pierisin protein resembles a classic bacterial $\mathrm{AB}$-toxin, with an enzymatically active $\mathrm{A}$ domain toxin that is delivered across the eukaryotic membrane through interaction with receptors on the cell surface by the B domain. Pierisin is closely related to the bacterial mosquitocidal toxin MTX NAD(+)dependent ADP-ribosyltransferase for which the crystal structure is known $^{29}$, with the closest pierisin sequence Pra57.2 having $32.56 \%$ identity to the structure sequence represented by the MTX holotoxin (PDB 2vse). The pierisin toxin transfers an ADP_rihnovl Page 4 of 16 


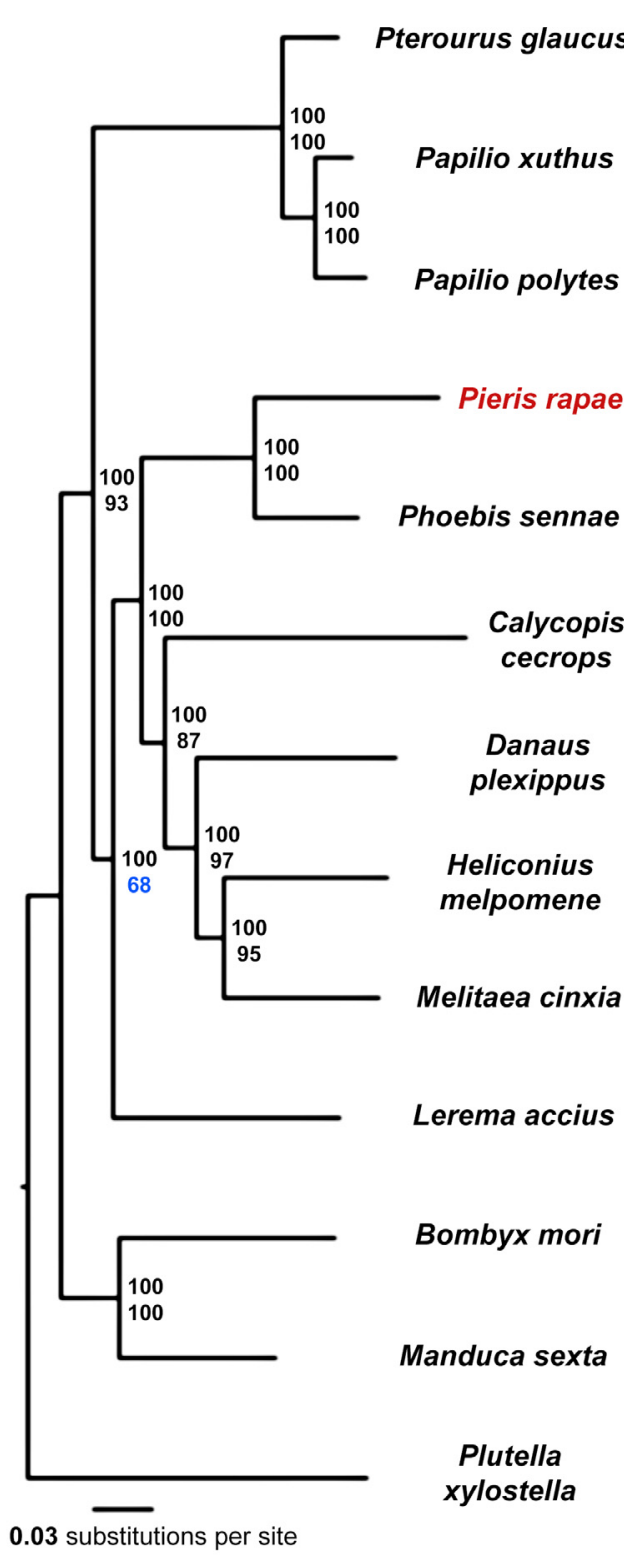

Seven copies of pierisin encoded by the Pieris rapae genome include an N-terminal ADP-ribosylation toxin followed by an inhibitory linker and four ricin domains. Mapping the Pieris rapae pierisin sequence conservations (in rainbow from conserved red to variable blue) to the MTX holotoxin structure revealed a strict conservation of the active site and residues surrounding the NADbinding site (Figure 3A, NAD in ball and stick), as well as conservation of the inhibitory linker in the region that replaces NAD (Figure 3B, linker in tube). The receptor-interacting ricin domains include QxW motifs that contribute to cytotoxicity (Figure 3B, spheres), and display relatively lower overall conservation than the catalytic domain. Thus, the receptor-interacting function might be diverging across the different copies of the gene, potentially allowing broader receptor specificity.

One copy of pierisin (Pra57.3) lacks the N-terminal ADP-ribosylation domain, and is composed of four ricin domains following an $\mathrm{N}$-terminal signal peptide, as validated by both the assembled genome and de novo assembled transcripts. In addition, the phylogenetic tree of the ricin domains in the eight copies of pierisin places this protein on the longest branch, suggesting that it has undergone rapid divergence from other pierisins and could have adopted a different function. Lacking the toxin domain, Pra57.3 may aid others toxins in entering the cells. Alternatively, it may be able to bind to the neutral glycosphingolipid receptors in the Pieris, and protect its own cells against other pierisins with the toxic ADP-ribosylation domains.

\section{Detoxifying nitrile-specifier proteins}

During feeding, the cabbage white butterfly larvae possess the ability to counteract toxic secondary metabolites produced by the food plant glucosinolate-myrosinase major chemical defense system. The hydrolysis reaction of plant myrosinase, which normally produces toxic isothiocyanates, is redirected to the production of nitriles in the presence of the larval gut nitrile-specifier protein (NSP) ${ }^{13}$. The exact role of NSP in nitrile production is debatable, the protein could either serve as an enzyme catalyzing the formation of nitriles from the aglycone intermediate or as an allosteric cofactor for myrosinase $^{13,33}$. The detoxifying NSP protein belongs to an insectspecific gene family consisting of variable tandem repeating units termed insect allergen-related repeats. While other Lepidoptera genomes appear to have no NSP genes, the Pieris genome encodes two copies of the NSPs (Supplementary Table S3B), each containing three copies of the insect allergen-related repeat domain ${ }^{34}$.

Figure 2. Phylogenetic tree of the Lepidoptera species with complete genome sequences. Majority-rule consensus tree of the maximal likelihood trees constructed by RAxML on the concatenated alignment of universal single-copy orthologous proteins. Numbers by the nodes refer to bootstrap percentages. The numbers above are obtained from complete alignments, the number below are obtained on $1 \%$ of the dataset.

moiety to 2'-deoxyguanosine residues in $\mathrm{DNA}^{30}$, while the ricin domains mediate interactions with neutral glycosphingolipid receptors, globotriaosylceramide (Gb3), and globotetraosylceramide $(\mathrm{Gb} 4)^{31}$. The toxin is thought to serve as a defense factor against parasitization by wasps ${ }^{12}$, but also induces apoptosis in cancer cell lines ${ }^{10,11,32}$.

Recently, a crystal structure of an insect allergen-related repeat domain from cockroach revealed a novel fold of twelve alphahelices (two 6 helical repeating units) encapsulating a large hydrophobic cavity. While the sequence identity between the allergen structure and each of the three Pieris NSP domains is relatively low ( $20 \%$ to each), their sequences can be confidently mapped to the known structure for functional inference. The cockroach allergen repeat cavity binds phospholipids such as phosphatidylethanolamine and phosphatidylglycerol when expressed in bacteria; and phosphatidylinositol (PI), phosphatidylserine and phosphatidylcholine when expressed in yeast. Alternately, the allergen purified from cockroach bound nonphosphorylated fatty acids such as palmitate, stearate, and oleate ${ }^{35}$, revealing a promiscuous binding 
capacity of the hydrophobic pocket. Such a promiscuous allergen binding activity might translate to the sequence-related NSP pockets, allowing binding of the various aglycone intermediates of the glucosinolate-myrosinase system.

Mapping the NSP-related protein sequences conservations to the allergen structure highlights invariant residues that both line the hydrophobic cavity of each domain, connect the repeating units, and connect adjacent $\alpha$-helices of the repeat (Figure 4, conserved residues colored red). The hydrophobic nature of the binding cavity is preserved in the NSP sequences, including numerous invariant hydrophobic residues that likely contribute to function. Conserved NSP residues also reside near the PO4 group of the phospholipid binding site (Figure 4D), including a YxxxW motif found in each repeat that should restrict the site to accommodate smaller ligands. In fact, the aglycone intermediate $\mathrm{SO} 4$ group and adjacent backbone atoms could mimic the PO4 in phospholipid (Figure 4E).

Alternately, the positions of invariant polar residues are limited to those that contribute to $\alpha$-helical interactions, to the linker regions that do not line the hydrophobic cavity, or to insertions not present in the template allergen-repeat structure. While an active site could potentially form between repeating domains of the NSP structure, no obvious clusters of catalytic residues could be mapped to the individual cavities of any of the domain repeats present in NSP. Potentially, the NSP cavities could accommodate binding the various aglycone intermediates produced by myrosinase, allowing time for spontaneous conversion to simple nitriles in the low $\mathrm{pH}$ of the gut. Thus, the NSP binding cavity could act in a pseudoenzymatic capacity, without traditional catalytic residues mediating chemistry.

\section{Inferring the population history from the SNP distribution pattern}

While the Pieris rapae genome is very heterozygous at $1.5 \%$, the distribution of these SNPs in the genome is highly non-random. The histogram of SNP fraction in 1000 bp genomic windows for both Pieris rapae and Papilio glaucus $(\mathrm{Pgl})$ is shown in Figure 4A. Since the reads from the highly heterozygous regions in the genome may not map well to the reference genome, such regions usually show lower-than-expected coverage and may hinder the detection of heterozygous positions. Therefore, in the analysis of both $\mathrm{Pgl}$ and Pra genomes, we focused on the genomic regions with coverage that are expected for a diploid genome. Compared to $\mathrm{Pgl}$, the Pra genome contains a much higher fraction of homozygous (SNP-free) regions (Figure 4B). This difference cannot be simply explained by the relatively low heterozygosity of Pra (1.5\% for Pra and $2.3 \%$ for $P g l$ ), because the probability of observing SNP-free segments longer than 500 bp is below $1 \%$ for genome of this size having $1.5 \%$ of heterozygosity (Figure 4C).

The Pra genome assembly contains a large portion (18.3\% of the total length) of SNP-free segments that are at least 1,000 bp. The average coverage of the SNP-free segments by the reads is 87 fold, which is higher than the average coverage of all the segments under study (coverage: 84 fold). Therefore, the lack of heterozygous positions does not arise from the failure of mapping reads from one haplotype to the reference genome which represents another haplotype in the highly heterozygous region. The $\mathrm{Pgl}$ genome contains only $1.55 \%$ long ( $>=1000 \mathrm{bp}$ ) SNP-free segments, which also support that the large portion of SNP-free segments in the Pra genome is not an artifact.
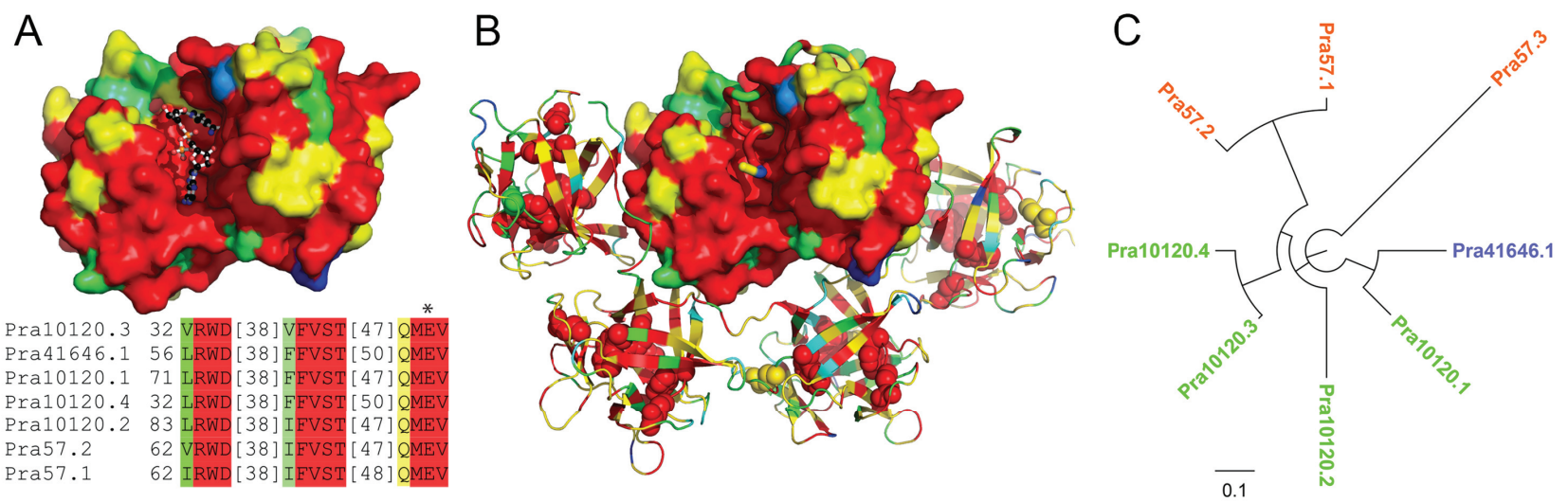

Figure 3. Pierisin conservation mapping to structure homolog and phylogenetic tree of the ricin domains. An alignment of the MTX holotoxin (PDB 2vse) sequence with the Pieris rapae pierisins was used to map sequence conservations calculated for the pierisin sequences. Conservations were colored in rainbow from blue (variable) to red (conserved). (A) The N-terminal ADP-ribosylation toxin domain (shown in surface representation) of the MTX holotoxin structure was superimposed with the cholera ADP-ribosylation toxin bound to its NAD+ substrate (shown in ball and stick) to highlight the NAD+ binding pocket. An alignment of residues that contribute to the binding pocket are depicted below the structure, highlighted according to conservation, with the catalytic E marked by an asterisk. (B) The N-terminal ADP-ribosylation toxin domain (shown in surface representation) of the MTX holotoxin is inhibited by a conserved inhibitory linker region (shown in tube) that blocks the substrate binding pocket. The C-terminal ricin-like domains of the holotoxin are depicted in cartoon, with corresponding sidechains of $\mathrm{Q} \times \mathrm{W}$ motifs depicted in sphere. (C) Phylogenetic tree of ricin domains in 8 pierisins from Pieris rapae. 

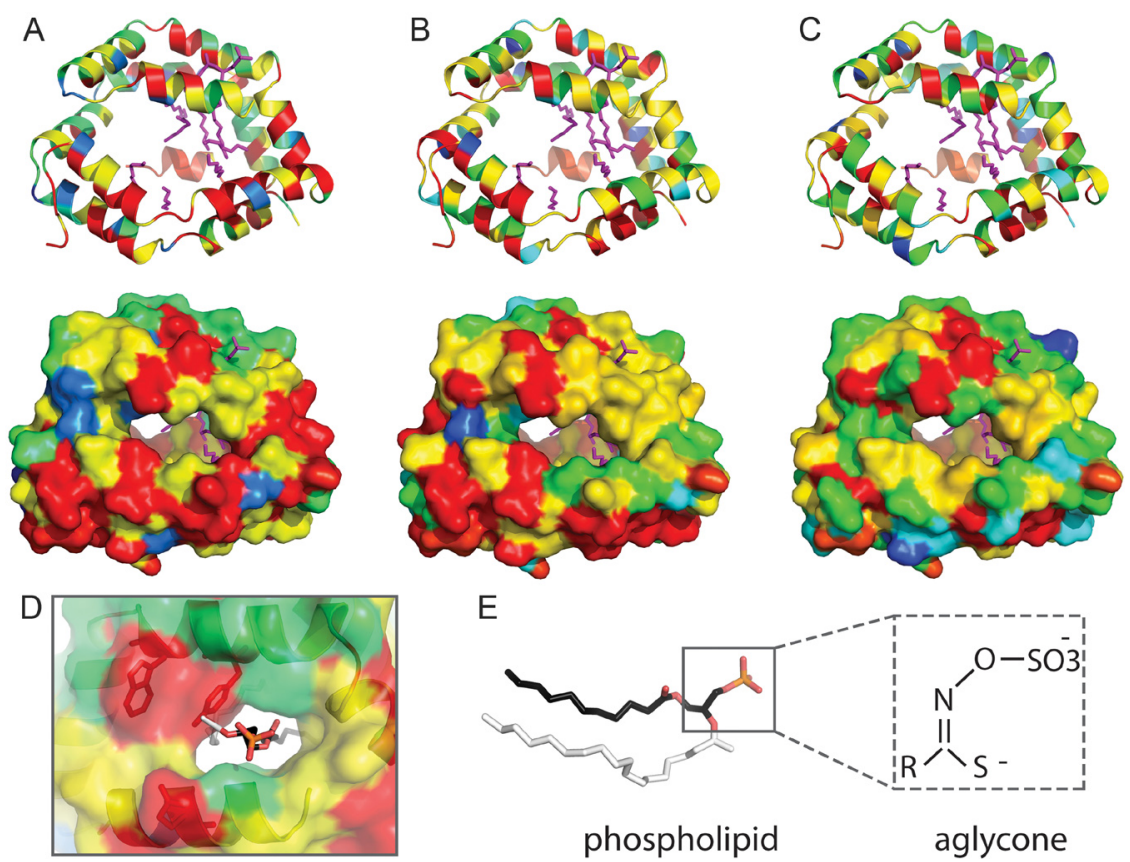

Figure 4. NSP family sequence conservation mapping to the insect allergen repeat structure. Residue conservation is colored from red (invariant) to blue (variable). The NSP N-terminal (A), middle (B), and C-terminal (C) domain repeats are represented in ribbon (upper panels) and surface (lower panels). Lipids from the insect allergen structure (4jrb) are in magenta sticks. (D) Zoom into the phospholipid binding site (N-terminal domain), with the head group colored by atom: P (orange), O (red), and C (black). The larger side group of the phospholipid ligand (white) is not compatable with the NSP YxxxW ${ }_{187}$ motif (shown in stick). (E) Comparison of phospholipid ligand (stick representation) with aglycone, with similar atom backbone orientations boxed. Sequence conservations were calculated using Al2 $\mathrm{CO}^{72}$ from an alignment of the following: Pieridae NSP1 and NSP2, together with AAR84202.1, ABY88944.1, ABX39547.1, ABX39554.1, ABY88945.1, ABX39555.1, ABX39546.1, ABX39549.1, ABX39537.1, ABX39552.1, ABX39553.1 from the NCBI Non-redundant protein database.

The median length of these segments is $38,000 \mathrm{bp}$, and the longest SNP-free region in the $P$. rapae draft genome is $339,000 \mathrm{bp}$. The presence of such high proportion of SNP-free segments indicates that this Pra specimen inherited a large proportion of identical alleles from its parents. Two scenarios could explain this: (1) this specimen is a result of recent inbreeding between brothers and sisters or between cousins (2) the population started from a very small number of individuals or has been through very severe bottlenecks and therefore the genetic diversity within the population is low. In order to distinguish between these two scenarios, we simulated them.

Inbreeding between brother and sister would result in the presence of $\sim 25 \%$ long homozygous segments, and this ratio goes down to $6.3 \%$ when the parents are cousins (Figure 6A). Inbreeding between half-blooded brother and sister from the same father (or mother) and whose mothers are sisters would result in $18.6 \%$ of homozygous segments. However, inbreeding between very close relatives would result in a very high median lengths of the SNP-free segments (Figure 6B), even if we assumed a very high recombination rate, $10 \mathrm{cM} / \mathrm{Mb}^{36}$. The median length of SNP-free segments in this scenario is still above 200,000 bp, which is much higher than the observed value, 38,000 bp. Therefore, inbreeding between close relatives cannot explain the observed SNP pattern.

The observed pattern of SNP-free segments agrees very well with the second scenario, i.e., the genetic diversity in the population is low, because the population started from very small number of individuals or has undergone very severe bottlenecks. The observed fraction and median lengths of the long SNP-free segments agrees very well with the simulated data assuming that the population started with 3 individuals (could be one female carrying spermatophores of two males) and has been developing for about 500 generations (Figure 6C, D). This supports the hypothesis that Pieris rapae came to America in $19^{\text {th }}$ century and the population started from very few individuals introduced by human activity. It cannot be excluded that the population started with a larger number of introduced individuals, but the genetic diversity was reduced due to severe bottlenecks, possibly early on, so only the progeny of one or two females gave rise to American populations of Pieris rapae. However, as a widely spread butterfly species over all different habitats that is somewhat resistant to parasite and toxins in plant, bottlenecks in the later stage of population history is not very likely. 

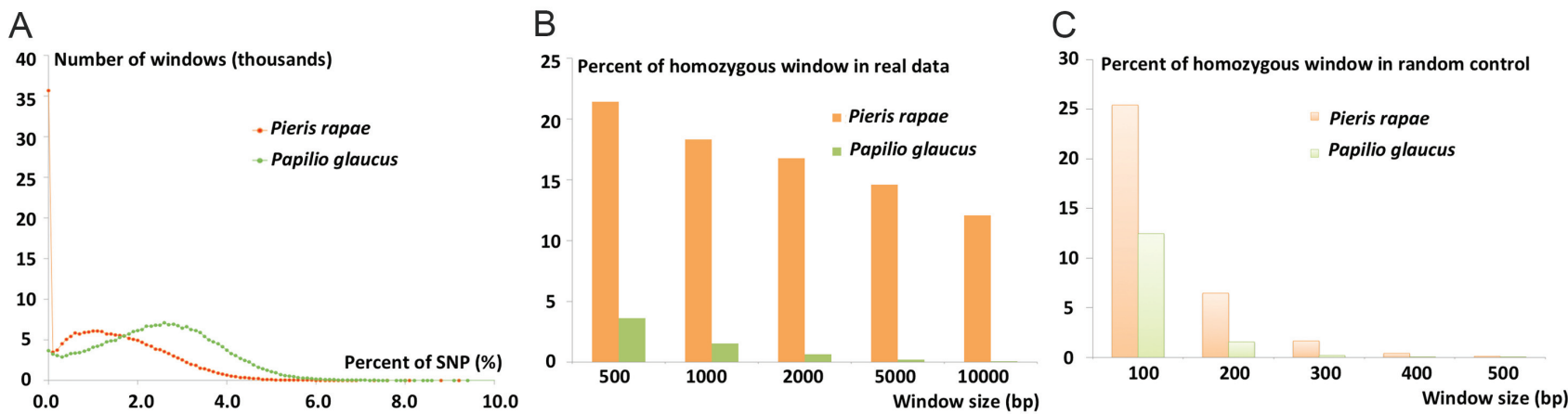

Figure 5. Comparison of SNP patterns in Pieris rapae (Pra) and Papilio glaucus (Pgl). (A) Histogram of SNP rates in 1000 bp windows from the Pra (red orange curve) and Pgl (green curve) genome. (B) The fraction of SNP-free long genomic windows in the Pra (orange bars) and $\mathrm{Pgl}$ (green bars) genomes. Pra genome has a much larger fraction of SNP-free windows than Pgl, especially when the window size goes beyond 1,000 bp. (C) The fraction of SNP-free genomic windows in Pra (light orange bars) and Pgl (light green bars) if the SNPs are distributed randomly. The fraction of such windows goes down to 0 when the window size is equal or bigger than $1000 \mathrm{bp}$.

Fraction of homozygous long (>= $1000 \mathrm{bp}$ ) segments

A 0.35

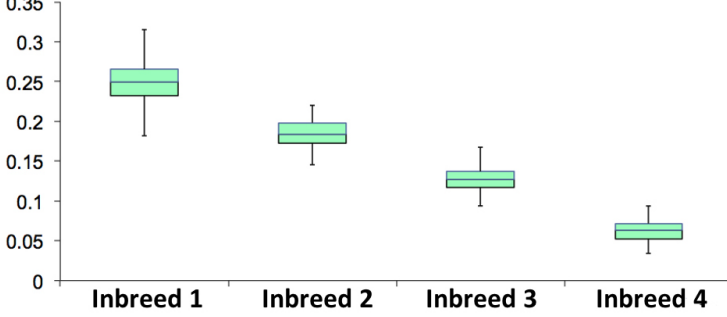

Fraction of homozygous long ( $>=1000 \mathrm{bp}$ ) segments

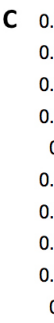

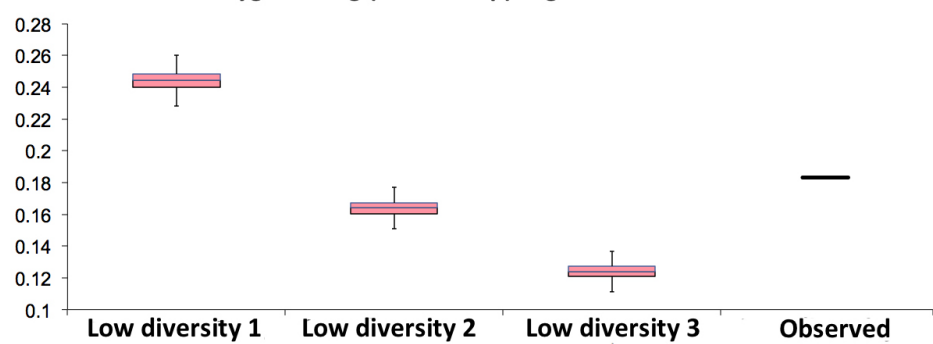

B Median length of homozygous long ( $>=1000 \mathrm{bp}$ ) segments

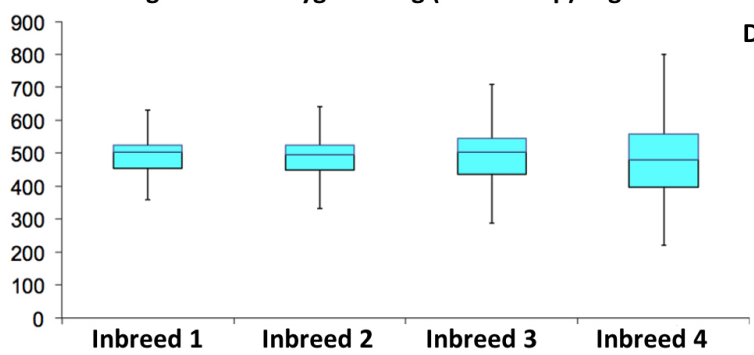

Median length of homozygous long (>= $1000 \mathrm{bp}$ ) segments

D

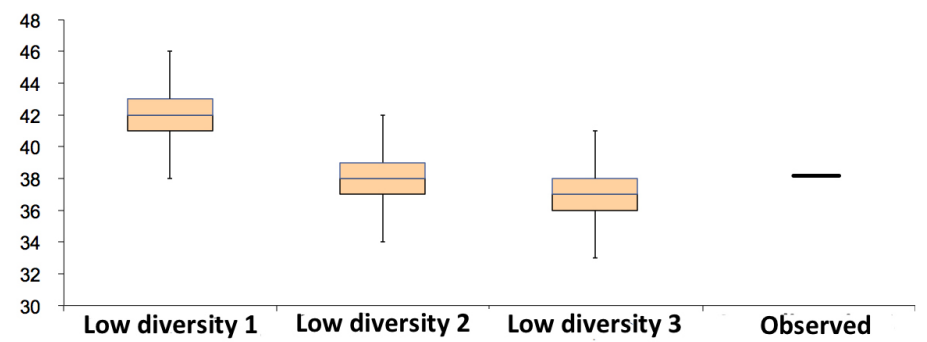

Figure 6. The fraction and median length of SNP-free segments observed in the genome supports the hypothesis that the population in America started with few individuals. (A) The fraction and (B) median length of SNP-free segments in the offspring of inbreeding between very close relatives. Inbreed 1: inbreeding between brother and sister; Inbreed 2: inbreeding between half-blooded brother and sister with common father (or mother) whose mothers (or fathers) are also sisters (or brothers) of each other. Inbreed 3: inbreeding between half-blooded brohter and sister with common father (or mother) whose mothers (or fathers) are not related. Inbreed 4: inbreeding between cousins. (C) The fraction and (D) median length of SNP-free segments in an individual from a in silico simulated population with low genetic diversity. Low diversity 1, 2, and 3: populations start from 2, 3, and 4 individuals, respectively. 500 generations with an effective population size of 50,000 were simulated. The recombination and mutation rates are $5 \mathrm{cM} / \mathrm{Mb}$ and $2.5 \mathrm{e}-3 / \mathrm{Mb}$ per generation.

Materials and methods

Library preparation and sequencing

Dataset 1. Major in-house scripts, archived at the time of publication

http://dx.doi.org/10.5256/f1000research.9765.d140486

Please see README.txt for a description of the files.
We removed and preserved the wings and genitalia of three freshly caught Pieris rapae specimens (NVG-3537 female, NVG-3842 and NVG-4113 males from USA: Texas: Dallas Co., Dallas, GPS 32.90516, -96.81546, collected on 5-Jun-2015, 30-Jun-2015, 17-Jul-2015, respectively), while the rest of the bodies were stored in RNAlater solution (Life Technologies Corporation, Grand Island, NY USA). Wings and genitalia of these specimens will be 
deposited in the National Museum of Natural History, Smithsonian Institution, Washington, DC, USA (USNM).

We used specimens NVG-3842 and NVG-4113 for sequencing and assembly the reference genome. We extracted genomic DNA from the tissue with the ChargeSwitch gDNA mini tissue kit (Invitrogen, Waltham, MA USA). $250 \mathrm{bp}$ and $500 \mathrm{bp}$ paired-end libraries were prepared using genomic DNA from specimen NVG-3842 with enzymes from NEBNext Modules (New England Biolabs Inc., Ipswich, MA USA) and following the Illumina TruSeq DNA sample preparation guide http://prodata.swmed.edu/LepDB/Protocol/illumina_Paired-End_Sample_Preparation_Guide.pdf. $2 \mathrm{~kb}, 6 \mathrm{~kb}$ and $15 \mathrm{~kb}$ mate pair libraries were prepared using genomic DNA from both NVG-3842 and NVG-4113 with a protocol similar to previously published Cre-Lox-based method ${ }^{37}$. For the $250 \mathrm{bp}, 500 \mathrm{bp}$, $2 \mathrm{kbp}, 6 \mathrm{kbp}$ and $15 \mathrm{kbp}$ libraries, approximately $250 \mathrm{ng}, 250 \mathrm{ng}$, $0.96 \mu \mathrm{g}, 1.92 \mu \mathrm{g}$ and $2.87 \mu \mathrm{g}$ of isolated DNA were used, respectively. We quantified the amount of DNA from all the libraries with the KAPA Library Quantification Kit (Kapa Biosystems, Inc., Wilmington, MA USA), and mixed 250 bp, 500 bp, 2 kbp, 6 kbp, $15 \mathrm{kbp}$ libraries at relative molar concentrations of 40:20:8:4:3. The mixed library was sequenced with PE-150 bp run using $64 \%$ of a single Illumina lane on HiSeq 2500 at UT Southwestern Medical Center Genomics and Microarray Core Facility.

Part of specimen NVG-3537 was used to extract RNA using QIAGEN RNeasy Mini Kit (QIAGEN Inc., Valencia, CA USA). We further isolated mRNA using NEBNext Poly(A) mRNA Magnetic Isolation Module (New England Biolabs Inc., Ipswich, MA USA). RNA-seq libraries were prepared with NEBNext Ultra Directional RNA Library Prep Kit (New England Biolabs Inc., Ipswich, MA USA) for Illumina following manufacturer's protocol. The RNA-seq library was sequenced with PE-150 bp run using $9 \%$ of an Illumina lane. The sequencing reads of all these libraries were deposited in the NCBI SRA database under accession SRP073457.

\section{Genome and transcriptome assembly}

We removed sequence reads that did not pass the purity filter and classified the remaining reads according to their TruSeq adapter indices to get individual sequencing libraries. Mate pair libraries were processed by the Delox script ${ }^{37}$ to remove the loxP sequences and to separate true mate pair from paired-end reads. All reads were processed by mirabait ${ }^{38} \mathrm{v} 4.0 .2$ to remove contamination from the TruSeq adapters, an in-house script to remove low quality portions (quality score $<20$ ) at the ends of both reads, JELLYFISH ${ }^{39}$ v2.2.3 to obtain k-mer frequencies in all the libraries, and QUAKE ${ }^{40}$ v0.3.5 to correct sequencing errors. The data processing resulted in seven libraries that were supplied to Platanus ${ }^{41}$ v1.2.4 for genome assembly: $250 \mathrm{bp}$ and $500 \mathrm{bp}$ paired-end libraries, $2 \mathrm{kbp}, 6 \mathrm{kbp}, 15 \mathrm{k}$ bp true mate pair libraries, a library containing all the paired-end reads from the mate pair libraries, and a single-end library containing all reads whose pairs were removed in the process.

We mapped these reads to the initial assembly with Bowtie $2^{42}$ v2.2.3 and calculated the coverage of each scaffold with the help of SAMtools ${ }^{43}$ v1.0. Many short scaffolds in the assembly showed coverage that was about half of the expected value; they likely came from highly heterozygous regions that were not merged to the equivalent segments in the homologous chromosomes. We removed them if they could be fully aligned to another significantly less covered region (coverage $>90 \%$ and uncovered region $<500 \mathrm{bp}$ ) in a longer scaffold with high sequence identity ( $>95 \%)$. Similar problems occurred in the Heliconius melpomene, Pterourus glaucus and Lerema accius genome projects, and similar strategies were used to improve the assemblies s $^{19,24,26}$.

The RNA-seq reads were processed using a similar procedure as the genomic DNA reads to remove contamination from TruSeq adapters and the low quality portion of the reads. Afterwards, we applied three methods to assemble the transcriptomes: (1) de novo assembly by Trinity ${ }^{44}$ v2.0.6, (2) reference-based assembly by TopHat $^{45}$ v2.0.10 and Cufflinks ${ }^{46}$ v2.2.1, and (3) reference-guided assembly by Trinity v2.0.6. The results from all three methods were then integrated by Program to Assemble Spliced Alignment $(\text { PASA })^{47}$ v2.0.2.

\section{Identification of repeats and gene annotation}

Two approaches were used to identify repeats in the genome: the RepeatModeler ${ }^{48}$ v1.0.7 pipeline and in-house scripts that extracted regions with coverage 3 times higher than expected. These repeats were submitted to the $\mathrm{CENSOR}^{49}$ server to assign them to the repeat classification hierarchy. The species-specific repeat library and all repeats classified in RepBase $^{50}$ v18.12 were used to mask repeats in the genome by RepeatMasker ${ }^{51} \mathrm{v} 4.0 .3$.

We obtained two sets of transcript-based annotations from two pipelines: TopHat followed by Cufflinks and Trinity followed by PASA. In addition, we obtained eight sets of homology-based annotations by aligning protein sets from Drosophila melanogaster ${ }^{2}$ and seven published Lepidoptera genomes (Bombyx mori, Lerema accius, Papilio polytes, Papilio glaucus, Papilio xuthus, Heliconius melpomene, and Danaus plexippus) to the Pra genome with exonerate $^{53}$ v2.2.0. Proteins from insects in the entire UniRef $90^{54}$ database were used to generate another set of gene predictions by genblastG ${ }^{55} \mathrm{v} 1.38$. We manually curated and selected 1256 confident gene models by integrating the evidence from transcripts and homologs to train de novo gene predictors: AUGUSTUS ${ }^{56} \mathrm{v} 3.1$, $\mathrm{SNAP}^{57}$ and GlimmerHMM ${ }^{58}$ v3.0.3. These trained predictors, the self-trained Genemark ${ }^{59}$ v2.3e and a consensus-based pipeline Maker $^{60}$ v2.31.8, were used to generate another five sets of gene models. Transcript-based and homology-based annotations were supplied to AUGUSTUS, SNAP and Maker to boost their performance. In total, we generated 16 sets of gene predictions and integrated them with EvidenceModeller ${ }^{47}$ v1.1.1 to generate the final gene models.

We predicted the function of Pra proteins by transferring annotations and GO-terms from the closest BLAST ${ }^{61}$ v2.2.30 hits $\left(\right.$ E-value $<10^{-5}$ ) in both the Swissprot ${ }^{62}$ database and Flybase ${ }^{63}$. Finally, we performed InterproScan ${ }^{64}$ v5.17-56.0 to identify conserved protein domains and functional motifs, to predict coiled coils, transmembrane helices and signal peptides, to detect homologous 3D structures, to assign proteins to protein families and to map them to metabolic pathways. 
Identification of orthologous proteins, analysis of unique genes for Pieris rapae, and phylogenetic tree reconstruction We identified the orthologous groups from 13 Lepidoptera genomes using OrthoMCL ${ }^{65}$ v2.0.9. The orthologous groups that contain only Pieris proteins were further investigated. Starting from these Pieris sequences, we attempted to identify their orthologs in other Lepidoptera genomes using reciprocal BLAST. Potential orthologs encoded by the genome but missed in the protein sets were predicted with the help of genblastG. Two groups of proteins, i.e. the pierisins and nitrile-specifier proteins discussed above turned out to be unique for Pieris. We manually curated the sequences for proteins in these two groups and submitted them to MESSA ${ }^{66}$ to perform secondary structure and disordered region prediction, domain identification and 3D structure prediction. We aligned the pierisin sequences using MAFFT v7.237 and built their evolutionary tree with RAxML ${ }^{67}$ v8.2.3 and visualized them in FigTree v1.4.2.

1845 orthologous groups consisted of single-copy genes from every species, and they were used for phylogenetic analysis. An alignment was built for each universal single-copy orthologous group using both global sequence aligner MAFFT ${ }^{68}$ and local sequence aligner BLASTP. Positions that were consistently aligned by both aligners were extracted from each individual alignment and concatenated to obtain an alignment containing 308,750 positions. The concatenated alignment was used to obtain a phylogenetic tree using RAxML. Bootstrap resampling of the aligned positions was performed to assign the confidence level of each node in the tree. In addition, in order to detect the weakest nodes in the tree, we reduced the amount of data by randomly splitting the concatenated alignment into 100 alignments (about 3,088 positions in each alignment) and applied RAxML to each alignment. We obtained a $50 \%$ majority rule consensus tree and assigned confidence level to each node based on the percent of individual trees supporting this node.

\section{Conservation mapping of NSP and pierisin}

NSP family sequences were collected using BLAST (PMID: 9254694) of the nr database with NSP1 as a query (default settings), keeping subject sequences with over $90 \%$ coverage. Conservations were calculated using Al2CO (PMID: 11524371) from a MAFFT (PMID: 24170399) alignment of the following: Pieridae NSP1 and NSP2, together with AAR84202.1, ABY88944.1, ABX39547.1, ABX39554.1, ABY88945.1, ABX39555.1, ABX39546.1, ABX39549.1, ABX39537.1, ABX39552.1, ABX39553.1. The NSP family includes three copies of an Insect allergen related repeat domain, which has a structure representative of the cockroach allergen Bla G 1 (PDB: 4jrp). The 4jrp sequence was aligned with each of the three repeat domains in the NSP family using PSIBLAST (PMID: 9254694) and HHPRED (PMID: 9626712) alignments as guides. Positional conservations for each domain were mapped to the B-factor column of the 4jrp structure coordinates with AL2CO (PMID: 11524371), and displayed with rainbow color scale (from blue variable to red conserved) using PyMOL Molecular Graphics System. Eight copies of pierisin from the sequenced genome were aligned as above with the related MTX holotoxin sequence HHPRED (PDB: 2vse), calculating and displaying positional conservations as above.

\section{Analysis of the SNP patterns in Pieris rapae}

We analyzed the SNPs in Pra and Papilio glaucus ( $P g l$ ) genomes using the same protocol, in which we mapped each read to the genomes and detected SNPs using the Genome Analysis Toolkit ${ }^{69}$ v3.5. The distribution of genome coverage by the reads in $100 \mathrm{bp}$ windows was plotted. For both Pra and Pgl genomes, this distribution shows two peaks. In addition to the main peak centered at the expected coverage for a diploid genome, there is an additional peak to the left that corresponds to highly divergent regions between the two homologous chromosomes. Owing to this sequence divergence, only the reads corresponding to the sequence of one of the homologous chromosomes can be mapped, which results in the lower-than-expected coverage. To analyze the distribution of SNPs, we used the regions whose coverage by the reads falls within the diploid peak.

We calculated the total number of positions with SNPs in such regions and simulated random distribution of these SNPs. The simulated distributions were used as controls. For the random control, experimental data, and the simulated genomes discussed below, we divided the scaffolds into 100, 200, 300, 400, 500, 1000, 2000, 5000, and 10000 bp windows (segments less than the window length at the ends of scaffolds are discarded), respectively, and calculated the presence of SNP-free windows. We concatenated neighboring SNP-free regions to obtain the longest SNP-free segments, and calculated the median length of these SNP-free segments.

Simulation of recent inbreeding and evolutionary history of the Pieris rapae population in America

We simulated Pieris rapae haplotypes by randomly introducing SNPs to the Pra reference genome, and the frequency of SNPs was set to be half of the frequency of heterozygous positions in the sequenced Pra individual (i.e., 0.7\%). Two simulated haplotypes were randomly paired to represent another simulated Pieris rapae individual, and the rate of heterozygous positions in the simulated individuals would be comparable to that observed in the sequenced specimen. To simulate the mating between two individuals, we assumed the two haplotypes of each individual could recombine at a certain rate (recombination rate) and generate a new haplotype that is inherited to the offspring.

The recombination rates of insects are rather variable, and the recombination rates for Bombyx mori, Heliconius melpomene and Heliconius erato are estimated to be 2.6, 5.5 and 6.1, respectively ${ }^{36}$. Therefore, we estimated the recombination rate for Pieris rapae to range between $1 \mathrm{cM} / \mathrm{Mb}$ and $10 \mathrm{cM} / \mathrm{Mb}$ per generation. To simulate recent inbreeding, we randomly select a recombination rate within this range. The mutations in this process are not introduced because the per generation mutation rate for butterflies are expected to be in the magnitude of 1e-9 mutation per base pair ${ }^{70}$, much lower than the existing variation between haplotypes. We simulated three scenarios of inbreeding: (1) between brother and 
sister (2) between cousins and (3) between half-blooded brother and sister.

To simulate the evolution of Pieris rapae population, we assumed the population started from a certain number of individuals $(2,3$ and 4). Several parameters would affect the population evolution, i.e., the number of generations since the species invaded America, the recombination rate, the mutation rate, and the effective population size. Pieris rapae was suggested to invade America in the second half of 19 century, and has 3-6 generations per year. Therefore, we assumed the number of generations to be 500. Based on the known values for other Lepidoptera species, we assumed the recombination rate to be $5 \mathrm{cM} / \mathrm{Mb}$ and the mutation rate to be $2.5 \mathrm{e}-9$. In the initial generations, the effective population size is mainly limited by the population size, and the population may undergo exponential growth. We assumed an exponential growth of the effective population size at rate of 10 fold per generation (each pair produce 20 offsprings). Later on, the population may reach its stationary phase, and the effective population size will be limited by the population structure and will not keep increasing. The effective population size of insects usually ranges between $1 \mathrm{e} 5$ and $1 \mathrm{e} 6^{71}$, and we assumed the effective population size to be $5 \mathrm{e} 5$ after the initial exponential growth phase.

\section{Data availability}

Sequencing reads were deposited in the NCBI SRA database under accession number SRP073457. The genome sequence was deposited at DDBJ/EMBL/GenBank under accession number LWME00000000.

Major in-house scripts and intermediate results are available at http://prodata.swmed.edu/LepDB/.
Archived scripts at the time of publication: 10.5256/ f1000research.9765.d140486 ${ }^{73}$

Please see README.txt for a description of the files.

\section{Author contributions}

J.S. and Q.C. designed and carried out the experiments, performed the computational analyses and drafted the manuscript; L.N.K. analyzed the proteins unique to Pieris; D.B. and Z.O. designed and supervised experimental studies; N.V.G. directed the project and drafted the manuscript. All authors wrote the manuscript.

\section{Competing interests}

The authors declare that they have no competing interests

\section{Grant information}

This work was supported in part by the National Institutes of Health (GM094575 to N.V.G) and the Welch Foundation (I-1505 to N.V.G).

The funders had no role in study design, data collection and analysis, decision to publish, or preparation of the manuscript.

\section{Acknowledgement}

We acknowledge Texas Parks and Wildlife Department (Natural Resources Program Director David H. Riskind) for the permit \#0802Rev that makes research based on material collected in Texas State Parks possible. We thank R. Dustin Schaeffer and Raquel Bromberg for critical suggestions and proofreading of the manuscript; Qian Cong is a Howard Hughes Medical Institute International Student Research fellow.

\section{Supplementary material}

Supplementary Table S1. Quality and composition of Lepidoptera genomes, related to Table 1.

Click here to access the data.

Supplementary Table S2. Statistics for sequencing data and data processing related to experimental procedures and genome annotation.

Click here to access the data.

\section{Supplementary Table S3. Protein sequences of pierisins and nitrile-specifier.}

Click here to access the data. 
1. Scudder SH: The introduction and spread of Pieris rapae in North America, 1860-1885. Boston, 1887; 53-69.

Publisher Full Text

2. Klots AB: Field Guide to the Butterflies of North America, East of the Great Plains. Houghton Mifflin, New York; 1978.

Reference Source

3. 2015 NABA Butterfly Count Report. (ed. Wander S.) North American Butterfly Association; 2015.

Reference Source

4. Bauer DL, Howe WH: The Butterflies of North America. 97 leaves of plates (Doubleday, Garden City, N.Y.). 1975; xiii: 633

Reference Source

5. Holland WJ: The Butterfly Book. Doubleday, New York. 1931. Reference Source

6. Scott JA: The Butterflies of North America: A Natural History and Field Guide. Stanford University Press: Stanford, Calif; 1986.

Reference Source

7. Gibbs GW: New Zealand Butterflies: Identification and Natural History. Collins, Auckland, New Zealand; 1980. Reference Source

8. Saunders DS: Insect Clocks. Pergamon Press Inc., New York; 1976. Reference Source

9. Heitzman RJ, Heitzman JE: Butterflies and Moths of Missouri. Missouri Department of Conservation, Jefferson City, MO; 1996. Reference Source

10. Kono $\mathrm{T}$, Watanabe $\mathrm{M}$, Koyama $\mathrm{K}$, et al:: Cytotoxic activity of pierisin, from the cabbage butterfly, Pieris rapae, in various human cancer cell lines. Cancer Lett. 1999; 137(1): 75-81.

PubMed Abstract | Publisher Full Text

11. Matsushima-Hibiya $\mathrm{Y}$, Watanabe $\mathrm{M}, \mathrm{K}$, $\mathrm{No} \mathrm{T}$, et al:: Purification and cloning of pierisin-2, an apoptosis-inducing protein from the cabbage butterfly, Pieris brassicae. Eur J Biochem. 2000; 267(18): 5742-50. PubMed Abstract | Publisher Full Text

12. Takahashi-Nakaguchi A, Matsumoto $Y$, Yamamoto M, et al: Demonstration of cytotoxicity against wasps by pierisin-1: a possible defense factor in the cabbage white butterfly. PLOS One. 2013; 8(4): e60539. PubMled Abstract | Publisher Full Text | Free Full Text

13. Wittstock U, Agerbirk N, Stauber EJ, et al.: Successful herbivore attack due to metabolic diversion of a plant chemical defense. Proc Natl Acad Sci U S A. 2004; 101(14): 4859-64.

PubMed Abstract | Publisher Full Text | Free Full Text

14. Watanabe M, Kono T, Matsushima-Hibiya $\mathrm{Y}$, et al:: Molecular cloning of an apoptosisinducing protein, pierisin, from cabbage butterfly: possible involvement of ADPribosylation in its activity. Proc Natl Acad Sci U S A. 1999; 96(19): 10608-13. PubMed Abstract | Publisher Full Text | Free Full Text

15. Orth $\mathrm{JH}$, Schorch $\mathrm{B}$, Boundy S, et al:: Cell-free synthesis and characterization of a novel cytotoxic pierisin-like protein from the cabbage butterfly Pieris rapae. Toxicon. 2011; 57(2): 199-207. PubMed Abstract | Publisher Full Text

16. Cong $Q$, Shen J, Warren AD, et al.: Speciation in Cloudless Sulphurs gleaned from complete genomes. Genome Biol Evol. 2016; 8(3): 915-31. PubMed Abstract | Publisher Full Text | Free Full Text

17. International Silkworm Genome Consortium: The genome of a lepidopteran model insect, the silkworm Bombyx mori. Insect Biochem Mol Biol. 2008; 38(12): 1036-45.

PubMed Abstract | Publisher Full Text

18. You M, Yue Z, He W, et al:: A heterozygous moth genome provides insights into herbivory and detoxification. Nat Genet. 2013; 45(2): 220-5. PubMed Abstract | Publisher Full Text

19. Heliconius Genome Consortium: Butterfly genome reveals promiscuous exchange of mimicry adaptations among species. Nature. 2012; 487(7405): 94-8.

PubMed Abstract | Publisher Full Text | Free Full Text

20. Zhan S, Merlin C, Boore JL, et al:: The monarch butterfly genome yields insights into long-distance migration. Cell. 2011; 147(5): 1171-85. PubMed Abstract | Publisher Full Text | Free Full Text

21. Tang W, Yu L, He W, et al.: DBM-DB: the diamondback moth genome database. Database (Oxford). 2014; 2014: bat087.

PubMed Abstract | Publisher Full Text | Free Full Text

22. Zhan S, Reppert SM: MonarchBase: the monarch butterfly genome database. Nucleic Acids Res. 2013; 41(Database issue): D758-63. PubMed Abstract | Publisher Full Text | Free Full Text

23. Duan J, Li R, Cheng D, et al.: SilkDB v2.0: a platform for silkworm (Bombyx mori) genome biology. Nucleic Acids Res. 2010; 38(Database issue): D453-6. PubMed Abstract | Publisher Full Text | Free Full Text

24. Cong Q, Borek D, Otwinowski Z, et al: Tiger Swallowtail Genome Reveals Mechanisms for Speciation and Caterpillar Chemical Defense. Cell Rep. 2015; pii: S2211-1247(15)00051-0.

PubMed Abstract | Publisher Full Text
25. Ahola V, Lehtonen $\mathrm{R}$, Somervuo $\mathrm{P}$, et al: The Glanville fritillary genome retains an ancient karyotype and reveals selective chromosomal fusions in Lepidoptera. Nat Commun. 2014; 5: 4737.

PubMed Abstract | Publisher Full Text | Free Full Tex

26. Cong $Q$, Borek $D$, Otwinowski $Z$, et al: Skipper genome sheds light on unique phenotypic traits and phylogeny. BMC Genomics. 2015; 16(1): 639. PubMed Abstract | Publisher Full Text | Free Full Text

27. Parra G, Bradnam K, Korf I: CEGMA: a pipeline to accurately annotate core genes in eukaryotic genomes. Bioinformatics. 2007; 23(9): 1061-7. PubMed Abstract | Publisher Full Text

28. Kawahara AY, Breinholt JW: Phylogenomics provides strong evidence for relationships of butterflies and moths. Proc Biol Sci. 2014; 281(1788): 20140970.

PubMed Abstract | Publisher Full Text | Free Full Text

29. Treiber N, Reinert DJ, Carpusca I, et al.: Structure and mode of action of a mosquitocidal holotoxin. J Mol Biol. 2008; 381(1): 150-9.

PubMed Abstract | Publisher Full Text

30. Takamura-Enya $\mathrm{T}$, Watanabe M, Totsuka $\mathrm{Y}$, et al:: Mono(ADP-ribosyl)ation of 2'-deoxyguanosine residue in DNA by an apoptosis-inducing protein, pierisin-1, from cabbage butterfly. Proc Natl Acad Sci U S A. 2001; 98(22): 12414-9. PubMed Abstract | Publisher Full Text | Free Full Text

31. Matsushima-Hibiya Y, Watanabe M, Hidari KI, et al.: Identification of glycosphingolipid receptors for pierisin-1, a guanine-specific ADP-ribosylating toxin from the cabbage butterfly. J Biol Chem. 2003; 278(11): 9972-8. PubMed Abstract | Publisher Full Text

32. Subbarayan S, Marimuthu SK, Nachimuthu SK, et al.: Characterization and cytotoxic activity of apoptosis-inducing pierisin- 5 protein from white cabbage butterfly. Int J Biol Macromol. 2016; 87: 16-27.

PubMed Abstract | Publisher Full Text

33. Burow M, Markert J, Gershenzon J, et al:: Comparative biochemical characterization of nitrile-forming proteins from plants and insects that alter myrosinase-catalysed hydrolysis of glucosinolates. FEBS J. 2006; 273(11): 2432-46

PubMed Abstract | Publisher Full Text

34. Fischer HM, Wheat CW, Heckel DG, et al.: Evolutionary origins of a novel host plant detoxification gene in butterflies. Mol Biol Evol. 2008; 25(5): 809-20. PubMed Abstract | Publisher Full Text

35. Mueller GA, Pedersen LC, Lin FB, et al: The novel structure of the cockroach allergen Bla $\mathrm{g} 1$ has implications for allergenicity and exposure assessment. $J$ Allergy Clin Immunol. 2013; 132(6): 1420-6.

PubMed Abstract | Publisher Full Text | Free Full Text

36. Wilfert L, Gadau J, Schmid-Hempel P: Variation in genomic recombination rates among animal taxa and the case of social insects. Heredity (Edinb). 2007; 98(4): 189-97.

PubMed Abstract | Publisher Full Text

37. Van Nieuwerburgh F, Thompson RC, Ledesma J, et al.: Illumina mate-paired DNA sequencing-library preparation using Cre-Lox recombination. Nucleic Acids Res. 2012; 40(3): e24.

PubMed Abstract | Publisher Full Text | Free Full Text

38. Chevreux B, Wetter T, Suhai S: Genome Sequence Assembly Using Trace Signals and Additional Sequence Information. Computer Science and Biology: Proceedings of the German Conference on Bioinformatics. 1999; 99: 45-56. Reference Source

39. Marçais G, Kingsford C: A fast, lock-free approach for efficient parallel counting of occurrences of $\boldsymbol{k}$-mers. Bioinformatics. 2011; 27(6): 764-70. PubMed Abstract | Publisher Full Text | Free Full Text

40. Kelley DR, Schatz MC, Salzberg SL: Quake: quality-aware detection and correction of sequencing errors. Genome Biol. 2010; 11(11): R116. PubMed Abstract | Publisher Full Text | Free Full Text

41. Kajitani R, Toshimoto $\mathrm{K}$, Noguchi $\mathrm{H}$, et al:: Efficient de novo assembly of highly heterozygous genomes from whole-genome shotgun short reads. Genome Res. 2014; 24(8): 1384-95.

PubMed Abstract | Publisher Full Text | Free Full Text

42. Langmead B, Salzberg SL: Fast gapped-read alignment with Bowtie 2. Nat Methods. 2012; 9(4): 357-9.

PubMed Abstract | Publisher Full Text | Free Full Text

43. Li H, Handsaker B, Wysoker A, et al:: The Sequence Alignment/Map format and SAMtools. Bioinformatics. 2009; 25(16): 2078-9. PubMed Abstract | Publisher Full Text | Free Full Text

44. Haas BJ, Papanicolaou A, Yassour M, et al.: De novo transcript sequence reconstruction from RNA-seq using the Trinity platform for reference generation and analysis. Nat Protoc. 2013; 8(8): 1494-512. PubMed Abstract | Publisher Full Text | Free Full Text

45. Kim D, Pertea G, Trapnell C, et al:: TopHat2: accurate alignment of transcriptomes in the presence of insertions, deletions and gene fusions. Genome Biol. 2013; 14(4): R36.

PubMed Abstract | Publisher Full Text | Free Full Text

46. Roberts A, Pimentel H, Trapnell C, et al.: Identification of novel transcripts in 
annotated genomes using RNA-Seq. Bioinformatics. 2011; 27(17): 2325-9. PubMed Abstract | Publisher Full Text

47. Haas BJ, Salzberg SL, Zhu W, et al: Automated eukaryotic gene structure annotation using EVidenceModeler and the Program to Assemble Spliced Alignments. Genome Biol. 2008; 9(1): R7.

PubMed Abstract | Publisher Full Text | Free Full Text

48. Smit AFA, Hubley R: RepeatModeler Open-1.0. 2008-2010.

Reference Source

49. Jurka J, Klonowski P, Dagman V, et al.: CENSOR--a program for identification and elimination of repetitive elements from DNA sequences. Comput Chem. 1996; 20(1): 119-21.

PubMed Abstract | Publisher Full Text

50. Jurka J, Kapitonov VV, Pavlicek A, et al:: Repbase Update, a database of eukaryotic repetitive elements. Cytogenet Genome Res. 2005; 110(1-4): 462-7.

PubMed Abstract | Publisher Full Text

51. Smit AFA, Hubley R, Green P: RepeatMasker Open-3.0. 1996-2010. Reference Source

52. Misra S, Crosby MA, Mungall CJ, et al:: Annotation of the Drosophila melanogaster euchromatic genome: a systematic review. Genome Biol. 2002; 3(12): RESEARCH0083.

PubMed Abstract | Publisher Full Text | Free Full Text

53. Slater GS, Birney E: Automated generation of heuristics for biological sequence comparison. BMC Bioinformatics. 2005; 6: 31. PubMed Abstract | Publisher Full Text | Free Full Text

54. Suzek BE, Huang $H, M c G a r v e y ~ P$, et al.: UniRef: comprehensive and nonredundant UniProt reference clusters. Bioinformatics. 2007; 23(10): 1282-8. PubMed Abstract | Publisher Full Text

55. She R, Chu JS, Uyar B, et al:: genBlastG: using BLAST searches to build homologous gene models. Bioinformatics. 2011; 27(15): 2141-3. PubMed Abstract | Publisher Full Text

56. Stanke M, Schöffmann O, Morgenstern B, et al.: Gene prediction in eukaryotes with a generalized hidden Markov model that uses hints from external sources. BMC Bioinformatics. 2006; 7: 62 .

PubMed Abstract | Publisher Full Text | Free Full Text

57. Korf I: Gene finding in novel genomes. BMC Bioinformatics. 2004; 5: 59 PubMed Abstract | Publisher Full Text | Free Full Text

58. Majoros WH, Pertea M, Salzberg SL: TigrScan and GlimmerHMM: two open source $a b$ initio eukaryotic gene-finders. Bioinformatics. 2004; 20(16): 2878-9.

PubMed Abstract | Publisher Full Text

59. Besemer J, Borodovsky M: GeneMark: web software for gene finding in prokaryotes, eukaryotes and viruses. Nucleic Acids Res. 2005; 33(Web Server issue): W451-4.

PubMed Abstract | Publisher Full Text | Free Full Text
60. Cantarel BL, Korf I, Robb SM, et al.: MAKER: an easy-to-use annotation pipeline designed for emerging model organism genomes. Genome Res. 2008; 18(1): 188-96.

PubMed Abstract | Publisher Full Text | Free Full Text

61. Altschul SF, Gish W, Miller W, et al.: Basic local alignment search tool. J Mol Biol. 1990; 215(3): 403-10. PubMed Abstract | Publisher Full Text

62. UniProt Consortium: Activities at the Universal Protein Resource (UniProt). Nucleic Acids Res. 2014; 42(Database issue): D191-8. PubMed Abstract | Publisher Full Text | Free Full Text

63. St Pierre SE, Ponting L, Stefancsik R, et al: FlyBase 102--advanced approaches to interrogating FlyBase. Nucleic Acids Res. 2014; 42(Database issue): D780-8. PubMed Abstract | Publisher Full Text | Free Full Text

64. Jones $\mathrm{P}$, Binns D, Chang HY, et al.: InterProScan 5: genome-scale protein function classification. Bioinformatics. 2014; 30(9): 1236-40. PubMed Abstract | Publisher Full Text | Free Full Text

65. Li L, Stoeckert CJ Jr, Roos DS: OrthoMCL: identification of ortholog groups for eukaryotic genomes. Genome Res. 2003; 13(9): 2178-89.

PubMed Abstract | Publisher Full Text | Free Full Text

66. Cong Q, Grishin NV: MESSA: MEta-Server for protein Sequence Analysis. BMC Biol. 2012; 10: 82 PubMed Abstract | Publisher Full Text | Free Full Text

67. Stamatakis A: RAxML version 8: a tool for phylogenetic analysis and postanalysis of large phylogenies. Bioinformatics. 2014; 30(9): 1312-3. PubMed Abstract | Publisher Full Text | Free Full Text

68. Katoh K, Standley DM: MAFFT multiple sequence alignment software version 7: improvements in performance and usability. Mol Biol Evol. 2013; 30(4): 772-80. PubMed Abstract | Publisher Full Text | Free Full Text

69. McKenna A, Hanna M, Banks E, et al.: The Genome Analysis Toolkit: a MapReduce framework for analyzing next-generation DNA sequencing data. Genome Res. 2010; 20(9): 1297-303.

PubMed Abstract | Publisher Full Text | Free Full Text

70. Keightley PD, Pinharanda A, Ness RW, et al.: Estimation of the spontaneous mutation rate in Heliconius melpomene. Mol Biol Evol. 2015; 32(1): 239-43. PubMed Abstract | Publisher Full Text | Free Full Text

71. Lynch M, Conery JS: The origins of genome complexity. Science. 2003; 302(5649): 1401-4. PubMed Abstract | Publisher Full Text

72. Pei J, Grishin NV: AL2CO: calculation of positional conservation in a protein sequence alignment. Bioinformatics. 2001; 17(8): 700-12. PubMed Abstract | Publisher Full Text

73. Shen J, Cong Q, Kinch L, et al.: Dataset 1 in: Complete genome of Pieris rapae, a resilient alien, a cabbage pest, and a source of anti-cancer proteins. F1000Research. 2016.

Data Source 


\title{
Open Peer Review
}

\section{Current Peer Review Status:}

\section{Version 1}

Reviewer Report 17 January 2017

https://doi.org/10.5256/f1000research.10527.r19401

(C) 2017 Sourakov A. This is an open access peer review report distributed under the terms of the Creative Commons Attribution License, which permits unrestricted use, distribution, and reproduction in any medium, provided the original work is properly cited.

\begin{abstract}
Andrei Sourakov
McGuire Center for Lepidoptera and Biodiversity, Florida Museum of Natural History, University of Florida, Gainesville, FL, USA

This paper is an important contribution to genomics. The choice of the cabbage white butterfly for this study is especially fitting, as chemical interactions between plants and herbivores have been recently studied on molecular level using this species and its relatives, with some very interesting insights into evolution of detoxification abilities in insects. The paper also addresses several additional questions from phylogenetics of Lepidoptera to the origins of the invasive exotic pest in North America. The authors provide creative solution for distinguishing between modern inbreeding and historical population bottleneck and interesting observations concerning recreation of evolutionary history using full-genome information. The potentially applied aspects of the paper - presence in the model organism of protein with anti-cancer properties and mapping of this protein - make this study a valuable foundation for future medical research.
\end{abstract}

I am also attaching the pdf of the article with minor suggestions concerning grammar/wording.

Competing Interests: No competing interests were disclosed.

I confirm that I have read this submission and believe that I have an appropriate level of expertise to confirm that it is of an acceptable scientific standard.

Reviewer Report 12 January 2017

https://doi.org/10.5256/f1000research.10527.r19231

(C) 2017 Mallet J. This is an open access peer review report distributed under the terms of the Creative Commons Attribution License, which permits unrestricted use, distribution, and reproduction in any medium, provided the original work is properly cited. 


\section{James Mallet}

Department of Organismic and Evolutionary Biology, Harvard University, Cambridge, MA, USA

Title and abstract: Appropriate, and suitable summary

Article content: This is another of many butterfly genome assemblies pioneered by the Nick Grishin group based on new short-read sequencing technology. It will form a useful contribution, and the fact that the butterfly is a major crop pest is a good justification for sequencing this particular species. Also the authors mention some novel biochemical pathways the insects use, hitherto not found in any other species. One set of proteins (pierisins) may be useful in inducing apoptosis and has already been suggested as an anti-cancer treatment - the discovery of more of these proteins in the current genome and transcriptomics work may be important in medicine. In addition, the "nitrile specifier proteins" are involved in inactivation of plant defences, and are another novel protein found in this species only. I'm not an expert on structural biology, but the authors apparently are, and so I'd defer to their knowledge of this area.

Pieris rapae is introduced from the old world, and so it might be expected to have undergone a population bottleneck or founder event. There was an intriguing pattern of homozygous patches in the genome that were suggested to be consistent with the hypothesis of such a bottleneck from a single female or maybe a couple of individuals having been introduced to North America in the last century. However, the simulation approach based on only a couple of genomes made this aspect of the study rather weak, especially since a major part of the article was devoted to these results. If the authors were really interested in this topic, they might have sampled resequence data more broadly, especially in the putative native range (presumably Europe?), as well as across North America. There are such studies from way back, for instance I quickly found this old study by googling, and the enzyme (protein) heterozygosities therein do not look particularly low by butterfly standards: Vawter, A.T., \& Brussard, P.F. 1984 ${ }^{1}$. There's also an intriguing difference between Southern and Western populations compared to Northeastern populations which may suggest greater heterozygosity in areas with climate more similar to Northern Europe. In other words, the long discussion in the paper about the heterozygosity and putative bottleneck in this study are misplaced, seem to ignore prior work, and seek to re-invent population genetic analyses rather than employing a more direct, standard approach to studying the putative bottleneck. I'd suggest greatly shortening this section, or doing the extra work to ensure that there are more comparisons with resequenced individuals, and more attention paid to prior work in this area.

How confident are the authors of their identification of repeats? I was a little unclear about the methods used here, but they appear to be using the assembly itself to identify repeats. This has very well known weaknesses in next-gen genome sequence assemblies. I recently examined the major Lepidoptera genomes for the presence of ribosomal DNA repeats, and found that none of these next-gen assembly genomes could not assemble the rDNA genes in any semblance of the way they ought to be. I think it's an assembly problem.

\section{Conclusions: see above}

Data: provision is adequate and standard for genome sequences.

\section{References}


1. Vawter AT, Brussard PF: Allozyme variation in a colonizing species: the cabbage butterfly Pieris rapae (Pieridae). Journal of Research on the Lepidoptera. 1984; 22: 204-216

Competing Interests: No competing interests were disclosed.

I confirm that I have read this submission and believe that I have an appropriate level of expertise to confirm that it is of an acceptable scientific standard.

The benefits of publishing with F1000Research:

- Your article is published within days, with no editorial bias

- You can publish traditional articles, null/negative results, case reports, data notes and more

- The peer review process is transparent and collaborative

- Your article is indexed in PubMed after passing peer review

- Dedicated customer support at every stage

For pre-submission enquiries, contact research@f1000.com 